\title{
Large-scale countrywide screening for tick-borne pathogens in field-collected ticks in Latvia during 2017-2019
}

Valentina Capligina, Maija Seleznova, Sarmite Akopjana, Lauma Freimane, Marija Lazovska, Rudolfs Krumins, Agnija Kivrane, Agne Namina, Darja Aleinikova, Janis Kimsis, Alisa Kazarina, Viktorija Igumnova, Antra Bormane and Renate Ranka*

\begin{abstract}
Background: Tick-borne diseases are of substantial concern worldwide in both humans and animals. Several hard tick species are of medical and veterinary interest in Europe, and changes in the range of tick species can affect the spread of zoonotic pathogens. The aim of the present study was to map the current prevalence and distribution pattern of ticks and related tick-borne pathogens in Latvia, a Baltic state in northern Europe.

Methods: Nearly 4600 Ixodes ricinus, I. persulcatus and Dermacentor reticulatus tick samples were collected in all regions of Latvia during 2017-2019 and were screened by molecular methods to reveal the prevalence and distribution pattern of a wide spectrum of tick-borne pathogens.

Results: New localities of D. reticulatus occurrence were found in western and central Latvia, including the Riga region, indicating that the northern border of D. reticulatus in Europe has moved farther to the north. Among the analyzed ticks, 33.42\% carried at least one tick-borne pathogen, and 5.55\% of tick samples were positive for two or three pathogens. A higher overall prevalence of tick-borne pathogens was observed in I. ricinus (34.92\%) and I. persulcatus (31.65\%) than in D. reticulatus (24.2\%). The molecular analysis revealed the presence of tick-borne encephalitis virus, Babesia spp., Borrelia spp., Anaplasma phagocytophilum and Rickettsia spp. Overall, 15 and 7 tick-borne pathogen species were detected in Ixodes spp. and D. reticulatus ticks, respectively. This is the first report of Borrelia miyamotoi in Latvian field-collected ticks.
\end{abstract}

Conclusions: This large-scale countrywide study provides a snapshot of the current distribution patterns of Ixodes and Dermacentor ticks in Latvia and gives us a reliable overview of tick-borne pathogens in Latvian field-collected ticks.

Keywords: Ixodes ricinus, Ixodes persulcatus, Dermacentor reticulatus, Tick-borne pathogens, Latvia

\section{Background}

Ticks are blood-feeding ectoparasites that are found worldwide. There is evidence that ticks parasitized dinosaurs almost 99 million years ago [1]. Ticks are the primary vectors of many viral and bacterial pathogens,

*Correspondence: renate_r@biomed.lu.lv

Latvian Biomedical Research and Study Centre, Ratsupites Street 1, Riga, Latvia protozoans and helminths, which pose significant threats to human and animal health [2]. Different tick species are able to transmit different diseases, and indepth cellular and molecular studies of both tick physiology and the pathogens that they transmit show that several intrinsic factors play an important role in the maintenance of the pathogens and the vector competence of tick species $[3,4]$. According to data from the 
European Centre for Disease Prevention and Control (ECDC), there are three hard tick species of medical and veterinary interest in north-eastern Europe: Ixodes ricinus; I. persulcatus; and Dermacentor reticulatus [5]. These ticks are carriers of a number of epidemiologically significant pathogens, such as Anaplasma phagocytophilum, Babesia spp., Borrelia spp., tick-borne encephalitis virus (TBEV), Rickettsia spp., Francisella tularensis, Bartonella spp., and Coxiella burnetii [6-9].

In Latvia, a Baltic state in northern Europe, three tickborne diseases are registered annually: Lyme disease (borreliosis, 481 cases in 2018, 24.9 cases per 100,000 individuals), tick-borne encephalitis (TBE; 169 cases in 2018, 8.7 cases per 100,000 individuals), and granulocytic ehrlichiosis, or anaplasmosis (27 cases in 2018, 1.4 cases per 100,000 individuals) (data from the Centre for Disease Prevention and Control of Latvia; https://spkc. gov.lv/). Babesiosis is not registered in Latvia as a human disease; however, it is playing an increasingly important role in veterinary medicine [10]. During the last decade, in addition to the commonly recorded $I$. ricinus and $I$. persulcatus ticks, the appearance and spread of D. reticulatus populations was reported in Latvia [11]. However, the current tick distribution and the diversity of tickassociated pathogens have not been fully characterized. Here, we present the results of large-scale, countrywide screening for tick-borne pathogens in field-collected ticks in Latvia during 2017-2019.

\section{Methods}

\section{Tick collection}

Host-seeking ticks were collected from ground vegetation by flagging during the tick activity period during 2017-2019 in all regions of Latvia. Tick sampling was conducted in different habitats, such as open landscapes, forests, abandoned fields and ecotones. The collection sites were geolocated. Maps were created using the publicly available Google Earth platform (http://www.googl e.co.uk/intl/en_uk/earth).

Tick samples were preserved in $70 \%$ ethanol. Ticks were identified to the species level, and their stage and sex were identified based on morphological characteristics [12, 13]. After morphological identification, the ticks were individually stored at $-20^{\circ} \mathrm{C}$.

\section{DNA and RNA extraction}

For DNA/RNA extraction, all samples were processed individually. The ticks were washed with $70 \%$ ethanol, dried, transferred to individual tubes and crushed in $300 \mu \mathrm{l}$ of sterile water. For DNA isolation, $50 \mu \mathrm{l}$ of digestion buffer [30 mM Tris- $\mathrm{HCl}$ (pH 8.0), 75 mM EDTA (pH 8.0), $0.3 \mathrm{M} \mathrm{NaCl}, 1.5 \% \mathrm{SDS}$ ] and $2.5 \mu \mathrm{l}$ of proteinase $\mathrm{K}$ $(20 \mathrm{mg} / \mathrm{ml})$ were added to $100 \mu \mathrm{l}$ of a tick suspension, and the mixture was incubated at $50{ }^{\circ} \mathrm{C}$ for $1 \mathrm{~h}$. DNA was extracted via the phenol/chloroform method and stored at $-20{ }^{\circ} \mathrm{C}$. Total RNA was extracted from a $100 \mu \mathrm{l}$ aliquot of a tick suspension using QIAzol reagent (Qiagen, Hilden, Germany), as described by the manufacturer. The RNA pellet was dissolved in $50 \mu \mathrm{l}$ of nuclease-free water (Fermentas, Vilnius, Lithuania) and stored at $-70^{\circ} \mathrm{C}$.

\section{PCR assays}

All samples were tested for the presence of Babesia spp., Borrelia spp., A. phagocytophilum and Rickettsia spp. using a nested polymerase chain reaction (PCR) targeting the $18 S$ rRNA, $16 S$ rRNA and glt $A$ genes, respectively, as previously described [10]. The presence of TBEV RNA in the samples was detected by reverse transcription realtime polymerase chain reaction (RT-qPCR) amplifying a fragment of the 3 ' NCR (non-coding region) as previously described [14].

To prevent PCR amplicon contamination, sample DNA/RNA preparation, reaction preparation, PCR amplification, and amplicon detection were all performed in separate areas using filter tips. Both negative and positive controls were included in all PCR amplification steps. As a negative control, PCR mixtures without DNA were used. As positive controls for PCR, the following specimens were used: Borrelia burgdorferi (sensu stricto) B31 strain (kindly donated by S. Bergström, Umeå, Sweden); A. phagocytophilum Webster strain (kindly donated by Friederike von Loewenich, Institute of Medical Microbiology, University of Freiburg, Germany); Rickettsia helvetica-positive tick sample Lv-P44, which we acquired in a previous study [15]; and Babesia canis-positive clinical sample Lv-dog 2 (positive DNA sample from dog blood), which we also detected in a previous study [16]. All primers and probes were synthesized by Metabion International AG (Munich, Germany) and all PCR reagents were purchased from Thermo Fisher Scientific (Waltham, MA, USA). The PCR products were visualized by electrophoresis in $1.5 \%$ agarose gels (TopVision Agarose; Thermo Fisher Scientific) in $1 \times$ Tris-acetate-EDTA buffer containing $0.2 \mu \mathrm{g} / \mathrm{ml}$ ethidium bromide under UV light.

\section{Sequencing}

Positive PCR amplicons were purified and analyzed by Sanger sequencing from both DNA strands using the BigDye Terminator v3.1 Cycle Sequencing Kit (Applied Biosystems, Waltham, USA) in an ABI Prism 3100 Genetic Analyzer (Perkin- Elmer, Waltham, USA). Sequence chromatograms were viewed and edited using Finch TV Version 1.4.0 software (Geospiza Inc., Seattle, USA). Primer sequences were omitted in all sample sequences. Pathogens were identified using the NCBI GenBank database (http://www.ncbi.nlm.nih.gov/genbank) and 
BLAST (Basic Local Alignment Search Tool) software [17] (http://www.ncbi.nlm.nih.gov/BLAST). Pathogen genotypes were assigned based on sequence similarity (99-100\%) with the corresponding genes of the reference strains.

\section{Statistical analysis}

All ticks were processed individually, and their prevalence was expressed as a percentage. The prevalence of pathogens was calculated with the $95 \%$ confidence intervals of a proportion by the "exact" method of Clopper and Pearson (GraphPad Prism 6; GraphPad Software, La Jolla, CA, USA). A P-value was calculated using the twosided Fisher's exact test (GraphPad Prism 6). P-values were adjusted for multiple testing by Holm correction in $\mathrm{R}$ using the $\mathrm{R}$ statistical package [18]. Values of $P \leq 0.05$ were considered significant.

\section{Results}

\section{Distribution of tick species}

In total, 4593 ticks were collected from 189 locations in Latvia (Fig. 1a). These ticks belonged to three species: I. ricinus (3840 samples: 1363 males, 1324 females and 1153 nymphs), I. persulcatus (158 samples: 77 males, 74 females and 7 nymphs), and D. reticulatus (595 samples: 172 males, 419 females and 4 nymphs). Based on geolocation data, the distribution of these species in Latvia was mapped. As expected, I. ricinus was present across the whole country, and the distribution of I. persulcatus was restricted to the eastern and northern-eastern Vidzeme and Latgale regions (Fig. 1b). Dermacentor reticulatus ticks were collected in the southern, central and western regions of Latvia. In addition, $D$. reticulatus was detected in geographically separate small localities in the Riga region (Fig. 1b, arrow). These results indicated that sympatric populations of $D$. reticulatus and $I$. ricinus ticks as well as D. reticulatus, I. ricinus and I. persulcatus ticks exist in several regions of Latvia. Additionally, a shift northward in the distribution of $D$. reticulatus in Latvia was observed.

\section{Pathogen prevalence in tick species}

The prevalence of tick-borne pathogens was studied and compared in the different tick species. The results are presented in Table 1 . The distribution of different pathogens is presented in Figs. 2 and 3. In total, 33.42\% $(1535 / 4593)$ of the field-collected ticks were pathogenpositive (34.92\% of I. ricinus; $31.65 \%$ of I. persulcatus; and $24.2 \%$ of D. reticulatus) and the differences were statistically significant (OR: 1.671, 95\% CI: $1.37-2.038, P<$ 0.0001 ) (Table 1). As expected, nymphs were pathogenpositive less often, and the pathogen load did not differ between males and females. Moreover, no pathogens were detected in $D$. reticulatus nymphs in our study.

The molecular analysis indicated the presence of 15 tick-borne pathogens in Ixodes ticks: TBEV; Ba. canis; $B a$. microti; Ba. venatorum; Ba. capreoli; A. phagocytophilum; $R$. helvetica; $R$. monacensis; $R$. raoultii; Bo. miyamotoi; Bo. afzelii; Bo. burgdorferi (s.s.); Bo. garinii; Bo. lusitaniae; and Bo. valaisiana. In D. reticulatus ticks, 7 pathogens were detected: TBEV; Ba. canis; $R$. helvetica; $R$. raoultii; Bo. afzelii; Bo. garinii; and A. phagocytophilum.

\section{Prevalence of Rickettsia spp.}

Rickettsia spp. were detected in the tick samples most frequently: $19.46 \%(894 / 4593)$ of the ticks were Rickettsia-positive. Ixodes persulcatus ticks were Rickettsia-positive significantly less frequently (7.59\%) than I. ricinus (19.45\%) and D. reticulatus (22.69\%) (OR: 3.02, 95\% CI: 1.669-5.466, $P<0.0001$ ) (Table 1). Among Rickettsia species, $R$. helvetica was most frequently detected; in total, $15.74 \%$ of ticks were positive for this species, and $R$. helvetica-positive samples were found in all regions of Latvia (Fig. 2a). The prevalence of $R$. helvetica in I. ricinus ticks was significantly greater $(17.76 \%)$ than that in either I. persulcatus (6.33\%) or D. reticulatus (5.21\%) ticks (OR: 3.75, 95\% CI: $2.708-5.193, P<0.0001)$. On the other hand, $R$. raoultii was associated mainly with $D$. reticulatus, in which this pathogen was detected in $17.82 \%$ of samples, in comparison with $2.11 \%$ of I. ricinus and $1.27 \%$ of I. persulcatus ticks (OR: 0.098, 95\% CI: 0.072-0.132, P $<0.0001)$. Rickettsia monacensis was detected only in $5 \mathrm{I}$. ricinus samples $(0.13 \%)$ (Table 1$)$.

\section{Prevalence of Babesia spp.}

The prevalence of Babesia pathogens was significantly higher in $I$. ricinus ticks than in $I$. persulcatus and $D$. reticulatus (2.53\% vs $0.63 \%$ and $0.34 \%$ ) (OR: $0.154,95 \%$ CI: $0.049-0.488, P=0.0002$ ) (Table 1). In total, four Babesia species were identified in I. ricinus ( $B a$. canis, $B a$. microti, $B a$. venatorum and $B a$. capreoli). Babesia microti and Ba. canis were the only Babesia species detected in $I$. persulcatus and D. reticulatus, respectively. Surprisingly, very similar proportions of field-collected $I$. ricinus and $D$. reticulatus ticks were $B a$. canis-positive in this study (0.91\% vs 0.34\%) (OR: 2.7269, 95\% CI: 0.6974-23.4610, $P=0.2223)$. However, $B a$. canis-positive samples were found only in areas with the sympatric occurrence of $I$. ricinus and D. reticulatus (Fig. 1d). Additionally, a nonuniform distribution pattern was observed for Ba. canis, as $B a$. canis-positive samples tended to form geographically separate, condensed foci independent of the tick species (Fig. 1d). 

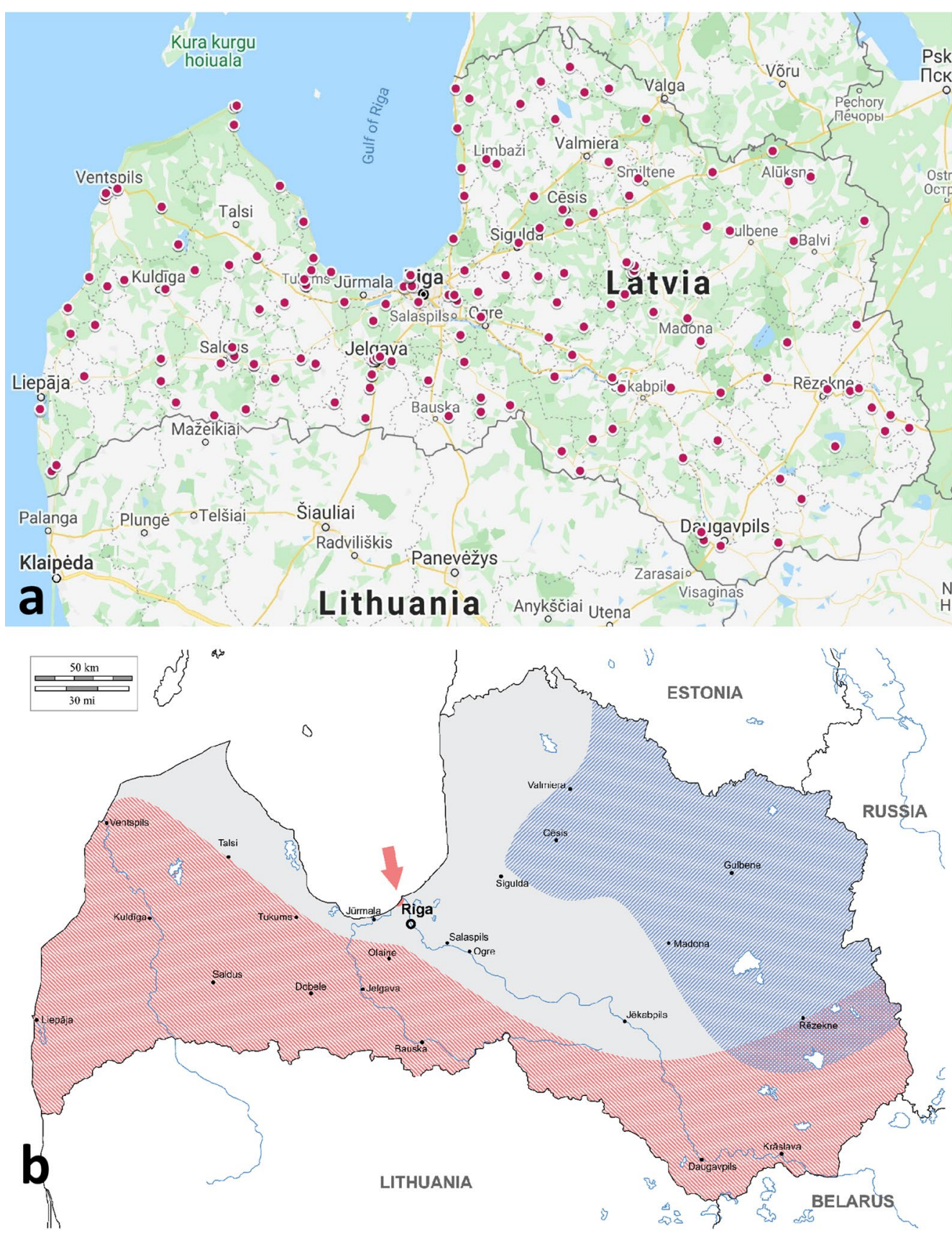

Fig. 1 Tick collection sites and distribution of tick species in Latvia. a Map of Latvia with the 189 tick sample sites, 2017-2019. Data were mapped using Google Earth. b Distribution of tick species in Latvia. The sympatric area for /xodes persulcatus and I. ricinus tick species is highlighted in blue. The sympatric area for Dermacentor reticulatus and I. ricinus tick species is highlighted in red

\section{Prevalence of TBEV}

The three tick-borne pathogens that cause the most common tick-borne diseases in Latvia, i.e. TBEV, Bo. burgdorferi (s.l.) and A. phagocytophilum, were all detected in tick samples in our study. Importantly, TBEV was detected in nearly identical proportions of I. ricinus, I. persulcatus and $D$. reticulatus samples $(0.65,0.63$ and $0.67 \%$, respectively) (Table 1). The geolocation data revealed that TBEV-positive ticks were found mostly in the western part of Latvia (Kurzeme region), and the TBEV distribution was markedly lower in northern and eastern regions (Fig. 3c). 


\section{Prevalence of $A$. phagocytophilum}

The etiological agent of anaplasmosis, $A$. phagocytophilum, was found in 1.2, 0.63 and $0.5 \%$ of I. ricinus, I. persulcatus and $D$. reticulatus ticks, respectively; the differences were not statistically significant. This pathogen was detected mainly in ticks in the western, central and northern regions of Latvia (Fig. 3d).

\section{Prevalence of Bo. burgdorferi (s.l.)}

The geolocation data showed that Lyme disease-causing pathogens were present in host-seeking ticks throughout the territory of Latvia (Fig. 3a). Borrelia burgdorferi (s.l.) group spirochaetes were detected in $15.99 \%$ and $23.42 \%$ of I. ricinus and I. persulcatus ticks, respectively, while only $1.01 \%(6 / 595)$ of $D$. reticulatus were Borreliapositive in this study; this difference was statistically significant (OR: 19.094, 95\% CI: 8.506-42.86, $P<0.0001$ ) (Table 1). Also, I. persulcatus ticks were Bo. burgdorferi (s.l.) positive significantly more frequently than $I$. ricinus (OR: 0.6225 , 95\% CI: 0.4228-0.9352, $P=0.0203$ ). Within this pathogen group, the genotyping analysis revealed the presence of Bo. afzelii, Bo. burgdorferi (s.s.), Bo. garinii, Bo. lusitaniae and Bo. valaisiana. The most abundant species was Bo. afzelii, which was detected in 9.35 and $15.19 \%$ of $I$. ricinus and I. persulcatus ticks, respectively. Borrelia afzelii was also the only Lyme disease-causing spirochaete present in several $D$. reticulatus ticks $(5 / 595$, $0.84 \%$ ) (Table 1). Additionally, $2.58 \%$ and $8.86 \%$ of $I$. ricinus and I. persulcatus were Bo. garinii-positive, while Bo. lusitaniae, Bo. valaisiana and Bo. burgdorferi (s.s.) were detected in $2.5 \%, 1.22 \%$ and $0.6 \%$ of $I$. ricinus ticks.

\section{Prevalence of Bo. miyamotoi}

The hard-tick-borne relapsing fever-causing pathogen Bo. miyamotoi was present solely in Ixodes ticks (1.15\% and $1.27 \%$ of $I$. ricinus and $I$. persulcatus, respectively); no Bo. miyamotoi-positive $D$. reticulatus samples were found in this study (Table 1). Similar to the Lyme disease spirochaetes, Bo. miyamoto $i$ was present in all regions of Latvia (Fig. 3b).

\section{Prevalence of co-infections in ticks}

In our study, $5.55 \%(255 / 4593)$ of the host-seeking tick samples were positive for more than one tick-borne infectious agent. Co-infection with two or three tick-borne pathogens, including two genotypes of the Bo. burgdorferi (s.l.) group, was detected in $6.3 \%, 3.16 \%$ and $1.34 \%$ of the $I$. ricinus, $I$. persulcatus and D. reticulatus samples, respectively, and the difference between I. ricinus and $D$. reticulatus was statistically significant (OR: 4.9341, 95\% CI: 2.4462-11.6218, $P<0.0001$ ) (Table 2). In total, 57 different pathogen combinations were detected (Additional file 1: Table S1). The most common co-infection detected in tick samples involved Bo. burgdorferi (s.l.) and Rickettsia spp. (2.94\%). Importantly, co-infection of Bo. burgdorferi (s.l.) with TBEV was found in $0.1 \%$ and $0.63 \%$ of I. ricinus and $I$. persulcatus ticks, and co-infection with three pathogens was detected in $0.55 \%(21 / 3840)$ of $I$. ricinus ticks in our study (Table 2 ).

\section{Discussion}

Here, the distribution of three tick species, I. ricinus, I. persulcatus and D. reticulatus, and the prevalence of tickassociated pathogens in Latvia was investigated. This is the most comprehensive countrywide study including host-seeking tick samples collected during 2017-2019.

\section{Distribution of tick species in Latvia}

As expected, all three epidemiologically important tick species were present in Latvia. The distribution of $I$. persulcatus was in accord with previous observations, as this tick species was found in northern and eastern parts of the country. The geolocation data of the tick collection sites revealed new localities of $D$. reticulatus occurrence in western and central Latvia, in addition to the previously observed locations [11]. Thus, the present study demonstrates that during the past few years, $D$. reticulatus has efficiently expanded its range in Latvia, and the northern border of D. reticulatus in Europe has moved farther north. Moreover, D. reticulatus has been detected in geographically separate new localities in the Riga region, indicating the development of new foci outside of the major distribution area. Similar to these findings, we reported in a recent study that from 2011 to 2016, D. reticulatus ticks were removed from dogs in western, southern and central parts of Latvia and the Riga region [10]. Outside of Latvia, the spread of $D$. reticulatus during the last decade has been notable in other European countries such as neighboring Lithuania $[9,11,19]$. Ticks spend most of their life in the environment, and all tick stages are dependent on a combination of climate variables, vegetation and the distribution and availability of suitable hosts. Climate change associated with warmer temperatures has a positive effect on tick survival in nature during nonparasitic periods of the life-cycle and can contribute to an increase in tick populations and the probability of spreading, establishment and survival in new geographical areas $[4,20]$.

Increases in human travel, animal transport, and environmental changes, including the establishment of new tick foci, are responsible for the emergence and/ or spread of numerous tick-borne pathogens [21]. In Europe, ticks are the most important vectors of human and animal infectious diseases and transmit more pathogens than any other arthropod [22]. Effective 


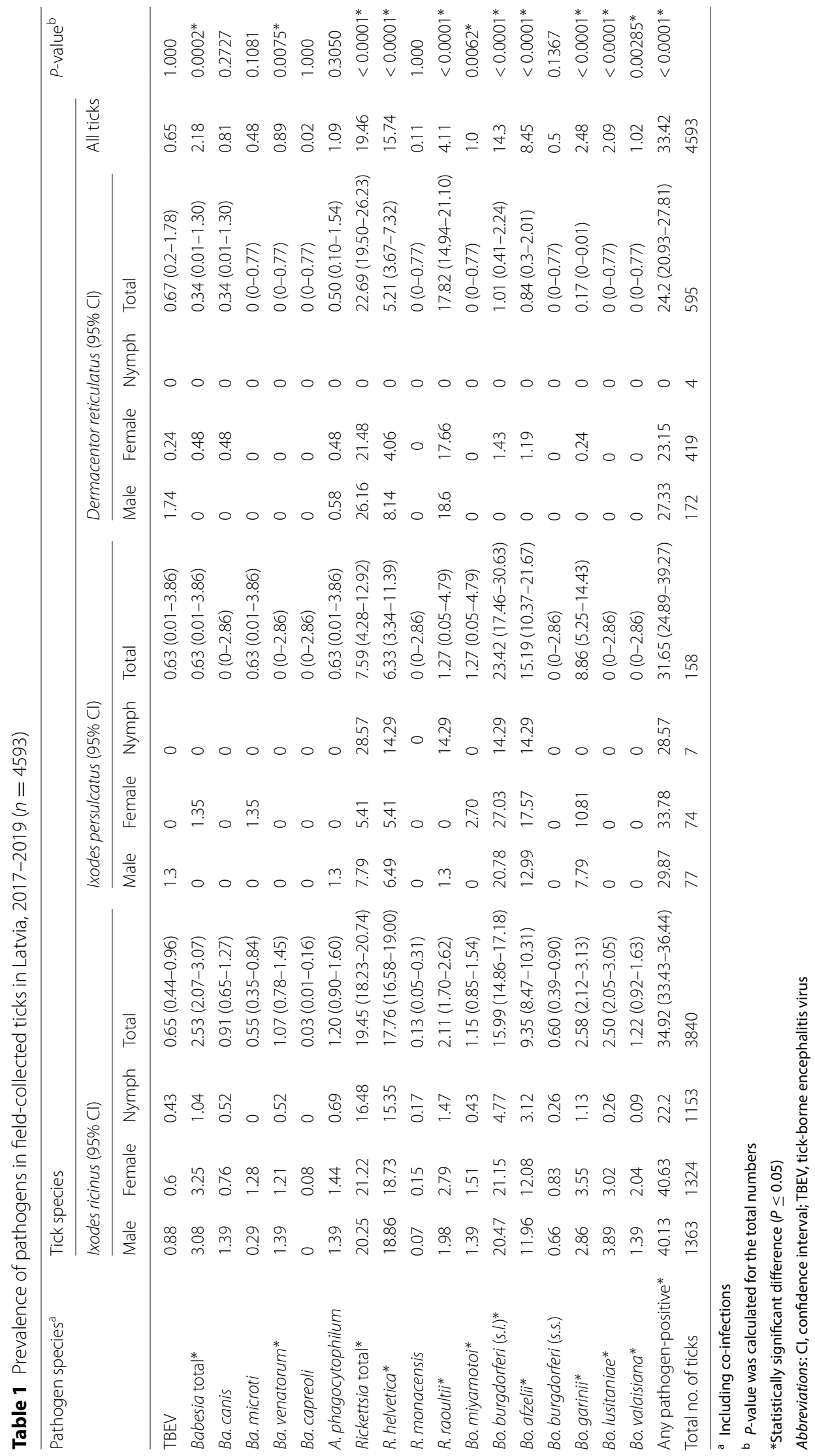




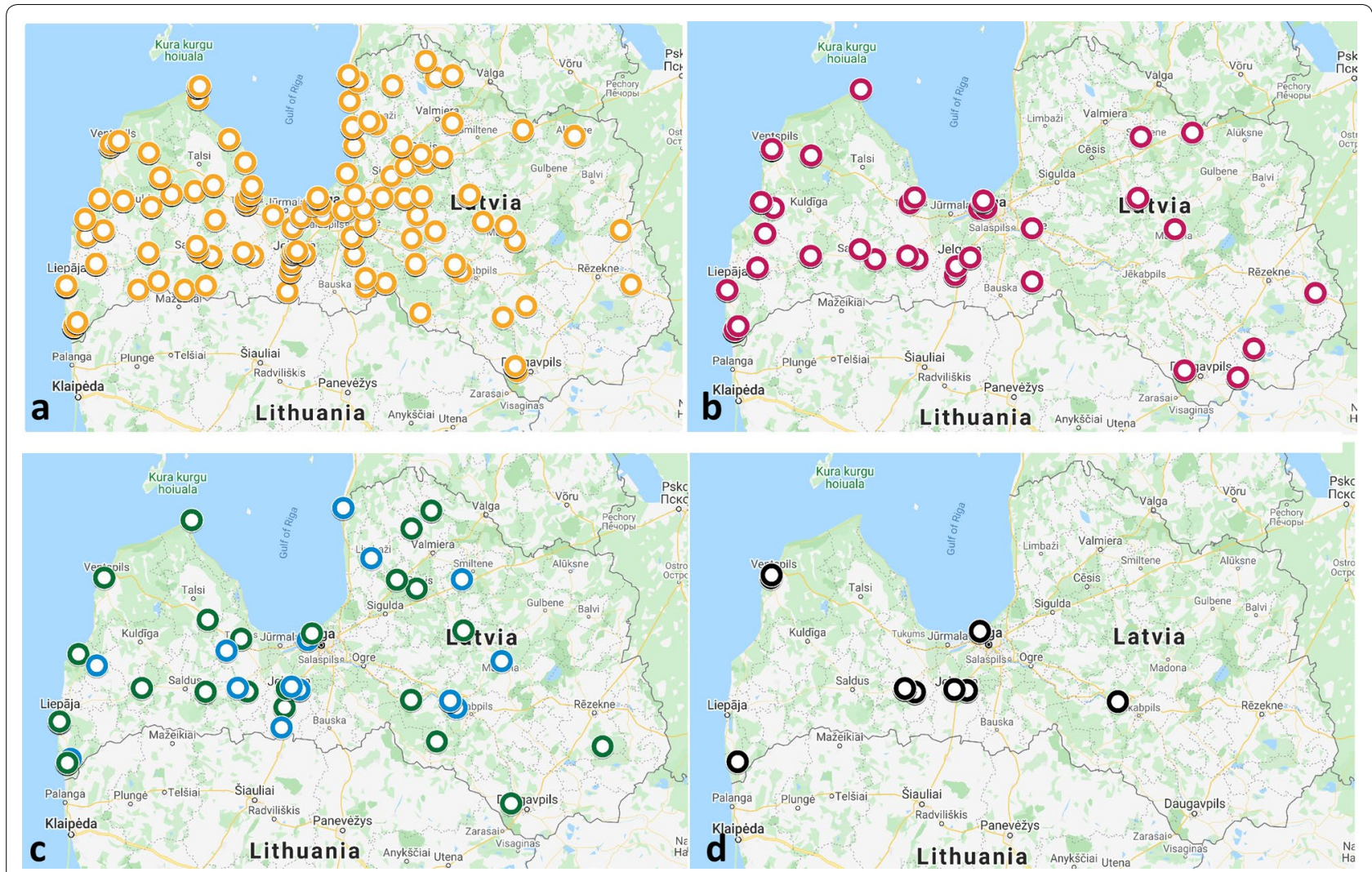

Fig. 2 Distribution of Rickettsia spp. and Babesia spp. in Latvia. a Rickettsia helvetica (orange circles). b Rickettsia raoultii (red circles). c Babesia microti (blue circles) and Babesia venatorum (green circles). $\mathbf{d}$ Babesia canis (black circles)

tick-based surveillance is essential for monitoring human and/or animal disease emergence [23]. However, studies on the prevalence of tick-borne pathogens in ticks are not available for all European countries, and the current tick situation in Latvia has not been fully characterized. Previous investigations of field-collected ticks in Latvia have been limited to Ixodes ticks and only a few pathogens and/or geographical locations, and the most recent studies on the prevalence of the highly medically important Borrelia spp. and TBEV in host-seeking ticks were published in 2004 and 2013, respectively [24-29]. Therefore, in the current largescale countrywide study, the prevalence of TBEV, Borrelia, Babesia, Anaplasma and Rickettsia pathogens was studied in all three medically important tick species.

\section{Rickettsia spp.}

Tick-borne rickettsiae are considered to be emerging; thus, it is important to obtain comprehensive data on the occurrence and prevalence of spotted fever group rickettsiae across Europe. In this study, Rickettsia spp. were detected in nearly $20 \%$ of all ticks. Three Rickettsia species were identified: $R$. helvetica, $R$. monacensis and $R$. raoultii. Rickettsia helvetica has been detected in Ixodes ticks in many European and Asian countries, and there is evidence that it may cause disease in humans [30]. On the other hand, cases of $R$. monacensis infection in humans have been reported in Spain, Italy, the Netherlands and South Korea [31]. In our study, both $R$. helvetica and $R$. monacensis were mainly associated with I. ricinus ticks, and infection rates were similar to those reported earlier in eastern European countries [32]. Additionally, $R$. helvetica was found in D. reticulatus ticks in our study (5.21\%), and $17.82 \%$ of the specimens of this tick species were $R$. raoultii-positive. Rickettsia raoultii is frequently detected in multiple tick species and, along with $R$. slovaca, is a causative agent of a syndrome in humans known as DEBONEL/TIBOLA (Dermacentorborne necrosis erythema and lymphadenopathy/tickborne lymphadenopathy), a newly recognized emerging disease [33, 34]. Thus, the results of this study confirmed that the spread of novel vectors could bring with it an additional risk of exposure to novel emerging pathogens. Moreover, small proportions of I. ricinus and I. persulcatus ticks were $R$. raoultii-positive in this study, and some 


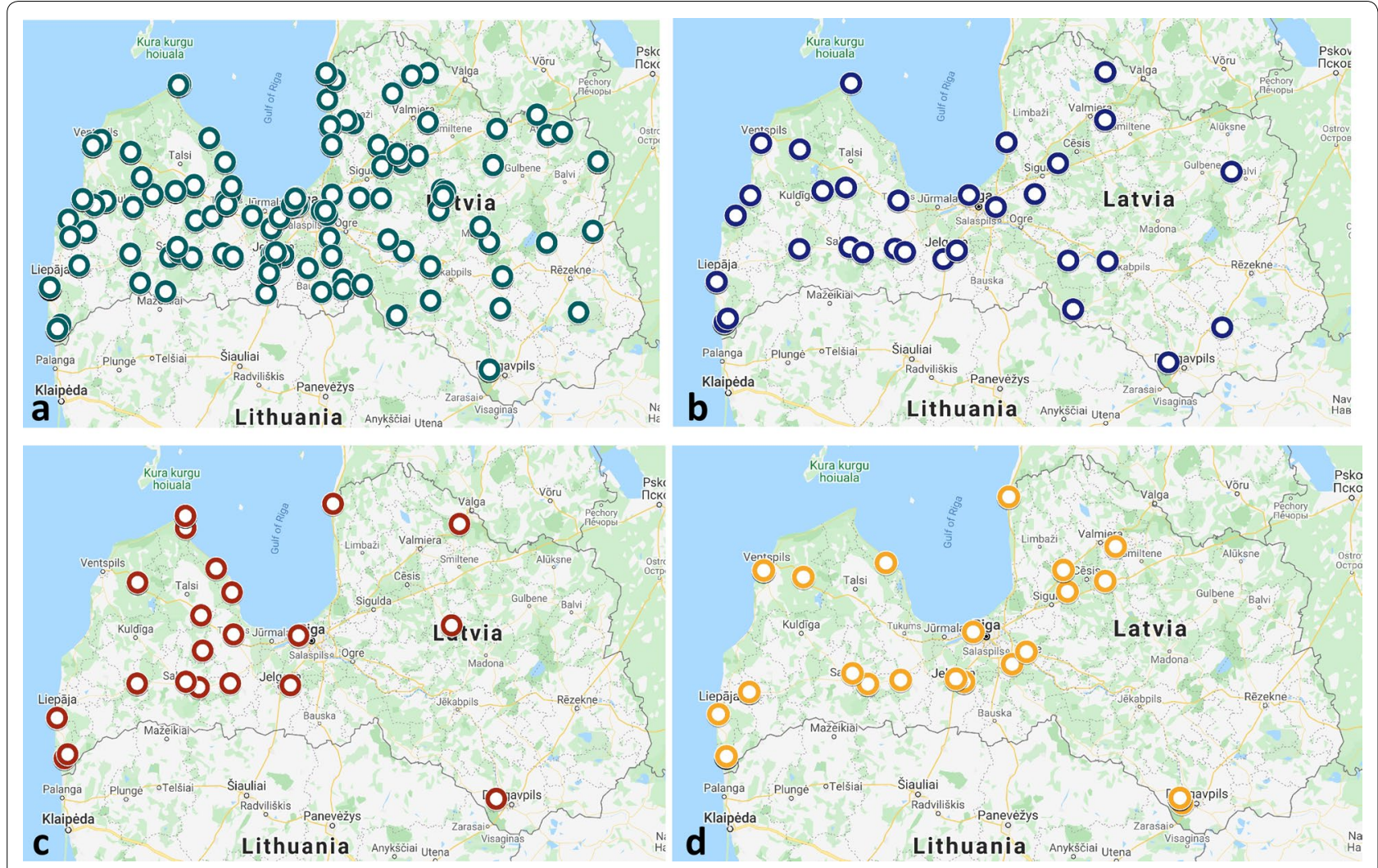

Fig. 3 Distribution of Borrelia spp., Anaplasma phagocytophilum and tick-borne encephalitis virus in Latvia. a Borrelia burgdorferi (s.l.) (green circles). b Borrelia miyamotoi (blue circles). c Tick-borne encephalitis virus (TBEV) (red circles). d Anaplasma phagocytophilum (yellow circles)

of these samples were collected in Latvian regions where D. reticulatus ticks are absent. These findings indicate the involvement of other factors, such as the availability of suitable reservoir animals, in the spread of this emerging pathogen.

\section{Anaplasma phagocytophilum}

The tick-borne pathogen A. phagocytophilum is of both public health and veterinary importance. This pathogen is a generalist, has a very broad range of hosts and causes disease in many mammalian species, including humans [35]. Human granulocytic anaplasmosis occurs in America, Europe and Asia [36]. The main vector of $A$. phagocytophilum in Europe is I. ricinus, but this pathogen has also been found in other tick species, including D. reticulatus $[37,38]$. The prevalence in questing ticks ranges from $0.4 \%$ to $33.9 \%$ in some localities, and due to the wide distribution of suitable hosts, A. phagocytophilum is found in all European countries [35]. In our study, A. phagocytophilum was identified at similar proportions in all three tick species, and its overall prevalence was $1.09 \%$. This finding confirmed the risk to humans and animals.

\section{Borrelia spp.}

In Latvian Ixodes ticks, Bo. miyamotoi, a member of the relapsing fever group spirochaetes, as well as the Lymedisease spirochaetes Bo. burgdorferi (s.s.), Bo. afzelii, Bo. garinii, Bo. valaisiana and Bo. lusitaniae were recorded, among which $B o$. afzelii was the predominant species (388/657, 59.1\%). The total prevalence of Bo. burgdorferi (s.l.) spirochaetes in I. persulcatus ticks was significantly higher than that in I. ricinus (23.42 vs 15.99\%); this result is in accordance with previous studies conducted in regions of sympatric tick occurrence [39, 40]. Additionally, in a meta-analysis conducted in Europe, the reported prevalence of Bo. burgdorferi (s.l.) in I. ricinus was $18.6 \%$ [41]. This is the first report of Bo. miyamotoi in field-collected ticks in Latvia. This pathogen was found in both $I$. ricinus and $I$. persulcatus ticks, and the prevalence rates $(1.15 \%$ and $1.27 \%$, respectively) were in accordance with the results of studies conducted in the neighboring countries of Estonia, Sweden and Finland [39, 42, 43]. Additionally, among the $595 \mathrm{D}$. reticulatus ticks, six (1.01\%) were positive for Bo. burgdorferi (s.l.); both Bo. afzelii and Bo. garinii were detected. The presence of Lyme disease pathogens in $D$. reticulatus ticks has been previously reported in European countries [18, 44]; thus, it is 


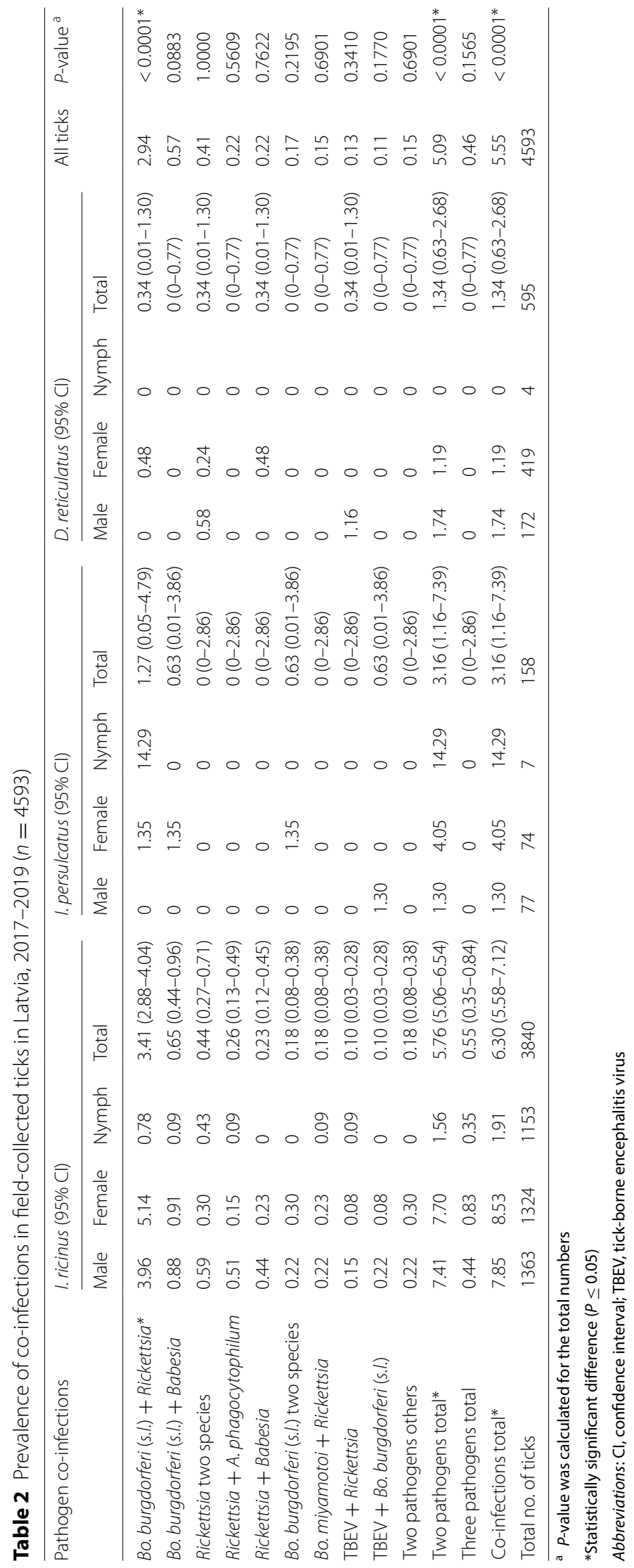


important to decipher their vector competence for these agents in future studies.

\section{TBEV}

Similar to the situation for Lyme disease pathogens, the vector competence of $D$. reticulatus for TBEV is still unclear. A recent study reported the repeated isolation of TBEV from adult D. reticulatus ticks in Germany, and it was suggested that $D$. reticulatus plays an equal role to $I$. ricinus in TBEV circulation when the two tick species are sympatric [45]. In our study, TBEV RNA was detected in three males and one female $D$. reticulatus tick, corresponding to an overall prevalence of $0.67 \%(4 / 595)$. Similar proportions of $I$. ricinus and I. persulcatus ticks (i.e. $0.65 \%$ and $0.63 \%$, respectively) were TBEV-positive. Previously, it was shown that from 1993 to 2002, the annual TBEV infection rate of field-collected adult ticks among I. ricinus adults varied between $1.7 \%$ and $26.6 \%$, while for I. persulcatus, it varied between $0 \%$ and $37.3 \%$ [25]. Another study reported that in Latvia, the difference in TBEV prevalence between the two Ixodes species was not statistically significant (1.02\% for I. persulcatus and $1.51 \%$ for I. ricinus) [28]. In the present study, the three tick species were infected with TBEV at equal rates. Thus, it can be suggested that all three tick species are currently involved in the circulation of TBEV in nature in sympatric regions. Additionally, the results of our study revealed the existence of TBEV-positive samples mainly in localities in the western Kurzeme region. This finding is in accordance with epidemiological data showing that the highest incidence of TBE in Latvian patients is observed in the same region (Kurzeme, 19.3 cases per 100,000) [46]. This finding highlights the importance of the surveillance of vector-borne pathogens in nature.

\section{Babesia spp.}

Within Babesia, Ba. microti, Ba. venatorum, Ba. capreoli and $B a$. canis were detected in this study. Both $B a$. microti and $B a$. venatorum are considered to pose a zoonotic risk to humans [47]. In total, 21 I. ricinus ticks (0.55\%) carried Ba. microti, and 41 (1.07\%) carried $B a$. venatorum. Additionally, a single $I$. persulcatus tick was $B a$. microti-positive in this study (0.63\%). Overall, these findings are similar to the results of our previous study in Ixodes ticks collected during 2005-2007, except that both $B a$. microti and $B a$. venatorum were detected in I. persulcatus ticks in the previous study [26]. The geolocation data indicated that both Babesia species were present in different regions of Latvia. On the other hand, $0.91 \%$ of I. ricinus ticks $(35 / 3840)$ carried $\mathrm{Ba}$. canis, the agent of canine babesiosis, which is usually strongly associated with $D$. reticulatus ticks. The presence of $B a$. canis in $I$. ricinus observed here is in accordance with a study conducted by Cieniuch et al. [48] in Poland, which showed that approximately $1 \%$ of field-collected $I$. ricinus ticks were infected, and also agrees with our recent study on ticks collected from dogs [10]. Interestingly, in the present study, the prevalence of $B a$. canis in field-collected $D$. reticulatus was very low, as only two samples out of $595(0.34 \%)$ were positive for this species. In contrast, $14.8 \%$ of $D$. reticulatus ticks removed from Latvian dogs were $B a$. canis-positive [10]. In a study by Radzijevskaja et al. [27], the overall prevalence of Babesia in D. reticulatus ticks from southern Latvia was $2.8 \%$; however, the prevalence of different species was not studied. Based on the molecular screening of field-collected ticks, the prevalence of $\mathrm{Ba}$. canis in adult $\mathrm{D}$. reticulatus ticks in Europe varies from $0 \%$ to $14.8 \%$ (see [6] for a review). In a recent study, Ba. canis was present in $0.9 \%$ of D. reticulatus ticks in north-western Europe [49]. Additionally, our analysis of the geolocation data for $\mathrm{Ba}$. canis-positive samples (disregarding the tick species) revealed the presence of several compact, geographically separated foci, suggesting an uneven, mosaic-like distribution in nature. Similarly, in a recent study in England, most of $D$. reticulatus ticks at a collection site related to an outbreak of canine babesiosis were $B a$. canis-positive, while in other locations, all but one of the ticks were $B a$. canis negative [50]. The existence of endemic foci of infected vectors indicates the existence of favorable conditions for the spread of parasitic diseases and their vectors.

\section{Prevalence of co-infections}

Importantly, the presence of two or three pathogens was found in a considerable portion of host-seeking ticks in our study. The total co-infection rate was 5.55\%; however, co-infections were found significantly more often in $I$. ricinus $(6.3 \%)$ than in D. reticulatus $(1.34 \%)$ ticks; $3.16 \%$ of $I$. persulcatus ticks were also positive for more than one pathogen. High variability of coinfections was observed. The coexistence of multiple pathogens in Ixodes ticks has been reported in the USA, Europe and Asia, and most co-infections involve two of the three major human pathogens, i.e. Bo. burgdorferi (s.l.), A. phagocytophilum and Babesia spp. (see [23] for a review). In Europe, co-infections are detected in up to $13 \%$ of Ixodes ticks [51]. Thus, the possibility of co-infection with more than one tick-borne pathogen exists for both humans and animals, particularly in endemic areas. Co-infection generally increases the diversity of presenting symptoms, and the disease course may be prolonged and more severe [52]. In our study, the co-infection of Bo. burgdorferi (s.l.) with Rickettsia was observed most frequently; however, the total number of different pathogen combinations 
was as high as 57 . Thus, awareness regarding possible co-infections in ticks should be increased, and further studies are needed, especially in the background of climate change and the emergence and spread of sympatric areas for Ixodes and Dermacentor tick species.

\section{Conclusions}

This countrywide, large-scale study provides a snapshot of the current distribution patterns of Ixodes and Dermacentor ticks in Latvia and gives us a reliable overview of tick-borne pathogens in field-collected ticks. The ongoing changes in tick abundance and distribution patterns along with changes in tick-borne pathogen diversity and prevalence indicate the importance of surveillance and future epidemiological studies.

\section{Supplementary information}

Supplementary information accompanies this paper at https://doi. org/10.1186/s13071-020-04219-7.

Additional file 1: Table S1. Prevalence of co-infections in field-collected ticks in Latvia, 2017-2019 $(n=4593)$.

\section{Abbreviations}

95\% Cl: 95\% confidence interval; EDTA: ethylenediaminetetraacetic acid; OR: odds ratio; PCR: polymerase chain reaction; s.l: sensu lato; s.s.: sensu stricto; TBE: tick-borne encephalitis; TBEV: tick-borne encephalitis virus.

\section{Acknowledgments}

We thank the Genome Centre, a core facility of the Latvian Biomedical Research and Study Centre for allowing us the use of their facilities. We thank Mārtinš̌ Vancāns for the transport service provided during tick sample collection.

\section{Authors' contributions}

$V C, A B$ and RR planned the study. VC, MS, SA, LF, ML, RK, AK, AN, DA, JK, AK, VJ, $A B$ and $R R$ performed sample collection, DNA extraction, $P C R$, real-time $P C R$, sequencing and data analysis. MS, AB, VC and RR wrote the manuscript. All read and approved the final manuscript.

\section{Funding}

This work was supported by the ERDF project No. 1.1.1.1/16/A/044. The funders of the study had no role in the study design, analysis or writing of the report.

\section{Availability of data and materials}

All data generated or analyzed during this study are included in this published article.

\section{Ethics approval and consent to participate}

Not applicable.

\section{Consent for publication}

Not applicable.

\section{Competing interests}

The authors declare that they have no competing interests.

Received: 18 February 2020 Accepted: 6 July 2020

Published online: 14 July 2020

\section{References}

1. Peñalver E, Arillo A, Delclòs X, Peris D, Grimaldi DA, Anderson SR, et al. Ticks parasitised feathered dinosaurs as revealed by Cretaceous amber assemblages. Nat Commun. 2018;9:472.

2. de la Fuente J, Estrada-Pena A, Venzal JM, Kocan KM, Sonenshine DE. Overview: ticks as vectors of pathogens that cause disease in humans and animals. Front Biosci. 2008;13:6938-46.

3. de la Fuente J, Antunes S, Bonnet S, Cabezas-Cruz A, Domingos AG, Estrada-Peña A, et al. Tick-pathogen interactions and vector competence: identification of molecular drivers for tick-borne diseases. Front Cell Infect Microbiol. 2017;7:114

4. Wikel SK. Ticks and tick-borne infections: complex ecology, agents, and host interactions. Vet Sci. 2018:5:60.

5. ECDC. Tick maps. Stockholm: European Centre for Disease Prevention and Control; 2019. https://www.ecdc.europa.eu/en/disease-vectors/surveillan ce-and-disease-data/tick-maps. Accessed 13 Jan 2020.

6. Földvári G, Široký P, Szekeres S, Majoros G, Sprong H. Dermacentor reticula tus: a vector on the rise. Parasit Vectors. 2016;9:314.

7. Rizzoli A, Silaghi C, Obiegala A, RudolfI, Hubálek Z, Földvári G, et al. Ixodes ricinus and its transmitted pathogens in urban and peri-urban areas in Europe: new hazards and relevance for public health. Front Public Health. 2014;2:251

8. Alekseev AN, Dubinina HV, Jushkova OV. First report on the coexistence and compatibility of seven tick-borne pathogens in unfed adult Ixodes persulcatus Schulze (Acarina: Ixodidae). Int J Med Microbiol. 2004;293(Suppl. 37):104-8.

9. Kjær LJ, Soleng A, Edgar KS, Lindstedt HEH, Paulsen KM, Andreassen ÅK, et al. A large-scale screening for the taiga tick, Ixodes persulcatus, and the meadow tick, Dermacentor reticulatus, in southern Scandinavia, 2016. Parasit Vectors. 2019;12:338

10. Namina A, Capligina V, Seleznova M, Krumins R, Aleinikova D, Kivrane A, et al. Tick-borne pathogens in ticks collected from dogs, Latvia, 2011-2016. BMC Vet Res. 2019:15:398.

11. Paulauskas A, Radzijevskaja J, Mardosaite-Busaitiene D, Aleksandravičienie A, Galdikas M, Krikštolaitis R. New localities of Dermacentor reticulatus ticks in the Baltic countries. Ticks Tick Borne Dis. 2015:6:630-5.

12. Filippova NA. Fauna SSSR Paukoobraznye. Ixodid ticks of the subfamily Ixodinae. Leningrad: Nauka; 1977.

13. Estrada-Peña A, Mihalca AD, Petney T. Ticks of Europe and North Africa: a guide to species identification. Berlin: Springer; 2018.

14. Schwaiger M, Cassinotti P. Development of a quantitative real-time RTPCR assay with internal control for the laboratory detection of tick borne encephalitis virus (TBEV) RNA. J Clin Virol. 2003;27:136-45.

15. Capligina V, Salmane I, Keišs O, Vilks K, Japina K, Baumanis V, et al. Prevalence of tick-borne pathogens in ticks collected from migratory birds in Latvia. Ticks Tick Borne Dis. 2014;5:75-81.

16. Berzina I, Capligina V, Baumanis V, Ranka R, Cirule D, Matise I. Autochthonous canine babesiosis caused by Babesia canis canis in Latvia. Vet Parasitol. 2013;196:515-8.

17. Altschul SF, Gish W, Miller W, Myers EW, Lipman DJ. Basic local alignment search tool. J Mol Biol. 1990;215:403-10.

18. Kohn M, Krücken J, McKay-Demeler J, Pachnicke S, Krieger K, von Samson-Himmelstjerna G. Dermacentor reticulatus in Berlin/Brandenburg (Germany): activity patterns and associated pathogens. Ticks Tick Borne Dis. 2019:10:191-206.

19. Mierzejewska EJ, Welc-Faleciak R, Karbowiak G, Kowalec M, Behnke JM, Bajer A. Dominance of Dermacentor reticulatus over Ixodes ricinus (Ixodidae) on livestock, companion animals and wild ruminants in eastern and central Poland. Exp Appl Acarol. 2015;66:83-101.

20. Estrada-Peña A, Ayllón N, de la Fuente J. Impact of climate trends on tickborne pathogen transmission. Front Physiol. 2012;3:64

21. Dantas-Torres F, Chomel BB, Otranto D. Ticks and tick-borne diseases: a one health perspective. Trends Parasitol. 2012;28:437-46.

22. Jongejan F, Uilenberg G. The global importance of ticks. Parasitology. 2004;129:\$3-14.

23. Diuk-Wasser MA, Vannier E, Krause PJ. Coinfection by Ixodes tick-borne pathogens: ecological, epidemiological, and clinical consequences. Trends Parasitol. 2016:32:30-42.

24. Ranka R, Bormane A, Salmina K, Baumanis V. Identification of three clinically relevant Borrelia burgdorferi sensu lato genospecies by 
PCR-restriction fragment length polymorphism analysis of 16S-23S ribosomal DNA spacer amplicons. J Clin Microbiol. 2004;42:1444-9.

25. Bormane A, Lucenko I, Duks A, Mavtchoutko V, Ranka R, Salmina K, et al. Vectors of tick-borne diseases and epidemiological situation in Latvia in 1993-2002. Int J Med Microbiol. 2004;293:36-47.

26. Capligina V, Berzina I, Bormane A, Salmane I, Vilks K, Kazarina A, et al. Prevalence and phylogenetic analysis of Babesia spp. in Ixodes ricinus and Ixodes persulcatus ticks in Latvia. Exp Appl Acarol. 2016;68:325-36.

27. Radzijevskaja J, Mardosaitè-Busaitienè D, Aleksandravičienè A, Paulauskas A. Investigation of Babesia spp. in sympatric populations of Dermacentor reticulatus and Ixodes ricinus ticks in Lithuania and Latvia. Ticks Tick Borne Dis. 2018;9:270-4.

28. Katargina O, Russakova S, Geller J, Kondrusik M, Zajkowska J, Zygutiene $\mathrm{M}$, et al. Detection and characterization of tick-borne encephalitis virus in Baltic countries and eastern Poland. PLoS One. 2013;8:e61374.

29. Paulauskas A, Radzijevskaja J, Rosef O. Molecular detection and characterization of Anaplasma phagocytophilum strains. Comp Immunol Microbiol Infect Dis. 2012;35:187-95.

30. Nilsson K, Elfving K, Påhlson C. Rickettsia helvetica in patient with meningitis, Sweden, 2006. Emerg Infect Dis. 2010;16:490-2.

31. Kim YS, Choi YJ, Lee KM, Ahn KJ, Kim HC, Klein T, et al. First isolation of Rickettsia monacensis from a patient in South Korea. Microbiol Immunol. 2017:61:258-63.

32. Radzijevskaja J, Paulauskas A, Aleksandraviciene A, Jonauskaite I, Stanko $M$, Karbowiak $G$, et al. New records of spotted fever group rickettsiae in Baltic region. Microbes Infect. 2015;17:874-8.

33. Parola P, Rovery C, Rolain JM, Brouqui P, Davoust B, Raoult D. Rickettsia slovaca and $R$. raoultii in tick-borne rickettsioses. Emerg Infect Dis. 2009;15:1105-8.

34. Portillo A, Santibáñez S, García-Álvarez L, Palomar AM, Oteo JA. Rickettsioses in Europe. Microbes Infect. 2015;17:834-8.

35. Stuen S, Granquist EG, Silaghi C. Anaplasma phagocytophilum-a widespread multi-host pathogen with highly adaptive strategies. Front Cell Infect Microbiol. 2013;3:31.

36. Bakken JS, Dumler JS. Human granulocytic anaplasmosis. Infect Dis Clin North Am. 2015:29:341-55.

37. Jahfari $S$, Coipan EC, Fonville M, van Leeuwen AD, Hengeveld P, Heylen $D$, et al. Circulation of four Anaplasma phagocytophilum ecotypes in Europe. Parasit Vectors. 2014;7:365.

38. Karbowiak G, Vichová B, Slivinska K, Werszko J, Didyk J, Pet́ko B, et al. The infection of questing Dermacentor reticulatus ticks with Babesia canis and Anaplasma phagocytophilum in the Chernobyl exclusion zone. Vet Parasitol. 2014;204:372-5.

39. Laaksonen M, Klemola T, Feuth E, Sormunen JJ, Puisto A, Mäkelä S, et al. Tick-borne pathogens in Finland: comparison of Ixodes ricinus and I. persulcatus in sympatric and parapatric areas. Parasit Vectors. 2018;11:556.
40. Alekseev AN, Dubinina HV, Antykova LP, Dzhivanyan TI, Rijpkema SG, Kruif NV, et al. Tick-borne borrelioses pathogen identification in Ixodes ticks (Acarina, Ixodidae) collected in St. Petersburg and Kaliningrad Baltic regions of Russia. J Med Entomol. 1998;35:136-42.

41. Rauter C, Hartung T. Prevalence of Borrelia burgdorferi sensu lato genospecies in Ixodes ricinus ticks in Europe: a metaanalysis. Appl Environ Microbiol. 2005;71:7203-16.

42. Geller J, Nazarova L, Katargina O, Järvekülg L, Fomenko N, Golovljova I. Detection and genetic characterization of relapsing fever spirochete Borrelia miyamotoi in Estonian ticks. PLoS One. 2012;7:e51914.

43. Wilhelmsson P, Fryland L, Börjesson S, Nordgren J, Bergström S, Ernerudh $J$, et al. Prevalence and diversity of Borrelia species in ticks that have bitten humans in Sweden. J Clin Microbiol. 2010;48:4169-76.

44. Ben I, Lozynskyi I. Prevalence of Anaplasma phagocytophilum in Ixodes ricinus and Dermacentor reticulatus and coinfection with Borrelia burgdorferi and tick-borne encephalitis virus in western Ukraine. Vector Borne Zoonotic Dis. 2019;19:793-801.

45. Chitimia-Dobler L, Lemhöfer G, Król N, Bestehorn M, Dobler G, Pfeffer M. Repeated isolation of tick-borne encephalitis virus from adult Dermacentor reticulatus ticks in an endemic area in Germany. Parasit Vectors. 2019;12:90

46. Zavadska D, Odzelevica Z, Karelis G, Liepina L, Litauniece ZA, Bormane A, et al. Tick-borne encephalitis: a 43-year summary of epidemiological and clinical data from Latvia (1973 to 2016). PLoS One. 2018;13:e0204844.

47. Vannier E, Krause PJ. Human babesiosis. N Engl J Med. 2012;366:2397-407.

48. Cieniuch S, Stańczak J, Ruczaj A. The first detection of Babesia EU1 and Babesia canis canis in Ixodes ricinus ticks (Acari, Ixodidae) collected in urban and rural areas in northern Poland. Pol J Microbiol. 2009;58:231-6.

49. Sprong $H$, Fonville $M$, Docters van Leeuwen $A$, Devillers E, Ibañez-Justicia A, Stroo A, et al. Detection of pathogens in Dermacentor reticulatus in northwestern Europe: evaluation of a high-throughput array. Heliyon. 2019;5:e01270.

50. de Marco MDMF, Hernández-Triana LM, Phipps LP, Hansford K, Mitchell ES, Cull B, et al. Emergence of Babesia canis in southern England. Parasit Vectors. 2017;10:241.

51. Swanson SJ, Neitzel D, Reed KD, Belongia EA. Coinfections acquired from Ixodes ticks. Clin Microbiol Rev. 2006;19:708-27.

52. Wilson KD, Elston DM. What's eating you? Ixodes tick and related diseases, part 3: coinfection and tick-bite prevention. Cutis. 2018;101:328-30.

\section{Publisher's Note}

Springer Nature remains neutral with regard to jurisdictional claims in published maps and institutional affiliations.
Ready to submit your research? Choose BMC and benefit from:

- fast, convenient online submission

- thorough peer review by experienced researchers in your field

- rapid publication on acceptance

- support for research data, including large and complex data types

- gold Open Access which fosters wider collaboration and increased citations

- maximum visibility for your research: over $100 \mathrm{M}$ website views per year

At BMC, research is always in progress.

Learn more biomedcentral.com/submissions 